\title{
Histopathology of experimental scuticociliatosis in turbot Scophthalmus maximus
}

\author{
L. Puig ${ }^{1, *}$, R. Traveset ${ }^{2}$, O. Palenzuela ${ }^{3}$, F. Padrós ${ }^{1,2}$ \\ ${ }^{1}$ Departament de Biologia Animal, de Biologia Vegetal i d'Ecologia, Facultat de Veterinària, \\ Universitat Autònoma de Barcelona, Bellaterra 08193, Spain \\ 22XRDA (Generalitat de Catalunya), Departament de Biologia Animal, de Biologia Vegetal i d'Ecologia, \\ Facultat de Veterinària,Universitat Autònoma de Barcelona, Bellaterra (Cerdanyola del Vallès), Barcelona 08193, Spain \\ ${ }^{3}$ Instituto de Acuicultura de Torre la Sal, Consejo Superior de Investigaciones Científicas, Ribera de Cabanes, \\ Castellón, Spain
}

\begin{abstract}
A scuticociliate strain (B-2), originally isolated from an outbreak in a turbot Scophthalmus maximus (= Psetta maxima) farm in Galicia (northwestern Spain) and maintained in axenic culture, was injected intracoelomically (lethal dose 80 equivalent, LD 80 ) in healthy turbot (50 g). Ciliateinjected fish were kept under controlled conditions in a recirculating seawater system and sampled on Days 1 through 8, 10, 12 and 14 postinfection (PI). Necropsies were conducted and included blood collection from the caudal vein and samples of liver, spleen, heart, digestive tract, kidney, gills, abdominal wall and neurocranium taken for routine histology. Mortality occurred from Day 6 until Day 12 PI and reached $66.7 \%$ by the end of the experiment. Presence of ciliates in the coelomic fluid was scarce until Day 4 PI. Parasitaemia was only observed from Day 5 until Day 10 PI and its incidence was always low. Presence of scuticociliates in tissue sections followed a progressive pattern of diffusion, with ciliates showing preference for loose connective tissue and also a clear haematophagous activity. The most severely affected organs were the pancreas and digestive tract. No special tropism for nervous tissues was observed in this study. The inflammatory reaction was variable depending on the tissue. After $3 \mathrm{wk}$, survivors had apparently managed to extinguish the infection.
\end{abstract}

KEY WORDS: Scophthalmus maximus · Psetta maxima · Turbot · Histophagous ciliates · Experimental infection · Pathogenesis

Resale or republication not permitted without written consent of the publisher

\section{INTRODUCTION}

Scuticociliates are saprophytic marine ciliates that may behave as facultative histophagous pathogens (Munday et al. 1997). They have been frequently described in disease outbreaks not only in fish species such as sea bass Dicentrarchus labrax (Dragesco et al. 1995), Japanese flounder Paralichthys olivaceous (Yoshinaga \& Nakazoe 1993), turbot Scophthalmus maximus (= Psetta maxima) (Dyková \& Figueras 1994) and southern bluefin tuna Thunnus maccoyii (Munday et al. 1997), but also in other aquatic animals such as crustaceans and molluscs (Armstrong et al. 1981).
Recently, systemic ciliatosis outbreaks caused by these protozoans have been described in the turbot industry, substantially increasing production costs due to mortality and morbidity (Iglesias et al. 2002). Several epidemiological, clinical and pathological descriptions of outbreaks have been published (Dyková \& Figueras 1994, Dragesco et al. 1995, Sterud et al. 2000, Iglesias et al. 2001). The taxonomy of this group has been recently revisited (Lynn \& Small 2000), though the variation in the criteria used has left it rather confusing (Álvarez-Pellitero et al. 2004). Prevention and control measures are needed to minimize severe economical impacts of ciliatosis outbreaks. Besides the strategies 
of prophylaxis and treatment, which are currently under study (Lee et al. 2004, Leiro et al. 2004a, Paramá et al. 2004a), a better understanding of the pathogenesis of the disease may be a useful approach to improving its control. With this aim, we studied pathogenesis of scuticocilatosis in turbot during an experimental infection. The scope of our research was not to determine or simulate the natural way of infection nor to study the dynamics of the disease, but to assure a standardized level of infection within the fish to allow the study of the histopathology of the infection in the different tissues under controlled conditions.

\section{MATERIALS AND METHODS}

Fish maintenance. Ninety-five healthy turbot weighing about $50 \mathrm{~g}$ each (mean $\pm \mathrm{SD}, 51.51 \pm 6.17 \mathrm{~g}$ ) were brought from a fish farm in Galicia to the aquaria of the wet laboratories of the Departament de Biologia Cel-lular, de Fisiologia i d'Immunologia at the Universitat Autònoma de Barcelona (UAB). The fish were randomly distributed in 7 square shaped tanks each filled with 1201 seawater and equipped with individual biological and mechanical filtration systems. Ten fish were allocated to each of 2 tanks as sentinel noninjected and control groups, and 15 turbot distributed in each of the remaining 5 tanks. Photoperiod was kept at $12 \mathrm{~h}$, water temperature ranged from 17 to $20^{\circ} \mathrm{C}$, $\mathrm{pH}$ ranged from 7.7 to 8.1 , salinity oscillated between 37 and $39 \%$, nitrite was maintained under $1.6 \mathrm{mg} \mathrm{l}^{-1}$ and un-ionized ammonia under $0.2 \mathrm{mg} \mathrm{l}^{-1}$. Optimum water quality was maintained by partial water changes. Fish were observed daily when fed with commercial pellets (Europa 22, Skretting) ad libitum.

Inocula. Scuticociliates (isolate B-2) were maintained at the Instituto de Acuicultura Torre de la Sal (IATS). They were originally isolated from diseased turbot farmed in Galicia, northwestern Spain, and maintained in axenic culture as described previously (Álvarez-Pellitero et al. 2004). A ciliate dose of 40000 ciliates per fish, equivalent to a lethal dose that would kill $80 \%$ of test fish $\left(\mathrm{LD}_{80}\right)$ according to a previous experiment (data not shown), was used in the inoculate. Each dose was inoculated in a vehicle of $0.2 \mathrm{ml}$ of Hanks' Balanced Salt Solution (HBSS) supplemented with $0.35 \% \mathrm{NaCl}$, penicillin, streptomycin and amphotericin B. The ciliates were harvested from the cultures, counted and adjusted to the final concentration, and transported to the UAB facilities for immediate use. Ciliate activity was checked microscopically before injection.

Infection. Fish were sedated (anaesthesia level 3) with $0.2 \mathrm{mg} \mathrm{l}^{-1}$ phenoxyethanol before any manipulation. Ciliate-injected fish from each of the 5 test tanks (15 per tank) received the scuticociliatid suspension by intracoelomic injection; those from the control tank (10 fish) received the same volume of HBSS without ciliates; and the remaining uninjected fish (10) were kept in the remaining tank as sentinels. As the objectives of the study were purely descriptive, the design was kept as simple as possible to reduce the animal number. To avoid cross contamination, each tank had an individual recirculation system and tools were disinfected before their use in a different tank.

Data collection. Of the 5 tanks containing ciliateinjected turbot one was used to monitor the daily and cumulative mortality throughout the experimental period. From the remaining tanks 4 fish were sampled periodically (1 fish taken randomly from each tank) on Days 1, 2, 3, 4, 5, 6, 7, 8, 10, 12 and 14 postinfection (PI). As an end point protocol, when moribund fish were noticed they were sedated and euthanized by severing the postcranial neural cord immediately. These fish were recorded as dead and processed in the same manner as the sampled fish.

All sampled fish were sedated and transported to the laboratory. Fish were weighed while fresh and blood from the caudal vein was extracted with heparinized syringes. After fish were euthanized, a skin scraping and a wet mount of coelomic fluid were immediately collected and studied under a microscope. Density and viability of ciliates were estimated visually. A systematic necropsy was performed and samples of different organs (liver, spleen, heart, digestive tract, kidney, gills, abdominal wall and neurocranium) were immediately collected and fixed for routine histology. From each blood sample, plasma corpuscular volumes $(\mathrm{PCVs})$ were determined in replicate after $24 \mathrm{~h}$ sedimentation (heparinized microcapillary tubes were filled with heparinized blood, sealed to prevent desiccation and stored vertically at $4^{\circ} \mathrm{C}$ for $24 \mathrm{~h}$ to ensure cell sedimentation; sedimentation was preferred to centrifugation in order to prevent haemolysis). Ciliate density was evaluated semiquantitatively in 3 blood smears stained with Methyl Blue. Haematoxylin and Eosin (H\&E) stained sections ( 3 to $5 \mu \mathrm{m}$ thick) of the different tissues were examined under the microscope; presence, location and density of ciliates, as well as type and extension of lesions, were recorded for each individual fish and tissue.

A total of 50 turbot were processed according to the protocol described: 3 served as controls, 41 fish were from the periodical samplings (on Day 14 PI only 1 remaining turbot could be sampled due to removal by previous sampling and mortality), 1 fish was found freshly dead on Day 3 PI, and the remaining fish corresponded to 5 injected survivors sampled on Day 20 PI. Daily mortalities were recorded for each tank and a wet mount of coelomic fluid was examined from each dead fish to assess ciliate presence. 


\section{RESULTS}

\section{Mortality and ciliate presence in dead fish}

At the end of the study, the cumulative mortality in the control tank reached $66.7 \%$, close to the expected $80 \%$ value (Fig. 1). Mortality was concentrated between Days 7 and 11 PI. In all cases scuticociliates were found in the coelomic fluid of dead fish, and appeared dead and more degenerated the more advanced the postmortem status of the fish was.

\section{Clinical signs and macroscopic lesions}

The only signs observed in infected fish were reduced food consumption and lethargy. Abdominal swelling was generally detected, and in most cases was haemorrhagic. This was confirmed in the necropsy

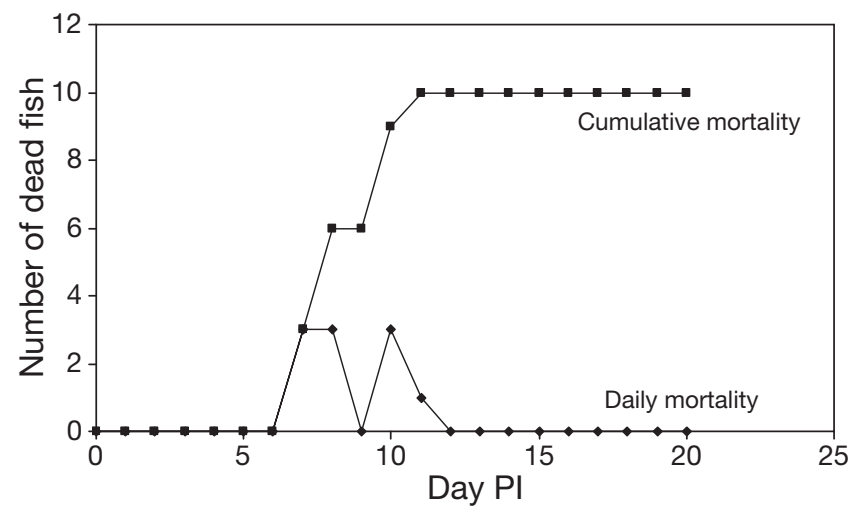

Fig. 1. Scophthalmus maximus. Daily and cumulative mortality of ciliate-injected turbot in mortality tank. PI: postinfection as ascites, frequently serosanguineous, were consistently noticed.

\section{Blood and coelomic fluid analysis}

The extent of scuticociliate presence in the coelomic fluid of sampled ciliate-injected fish is shown in Table 1. During the first $4 \mathrm{~d}$ PI ciliates were only found in $50 \%$ of the samples, commonly in reduced numbers and with decreased motility or abnormal morphology. On Days 5 and 6 PI ciliates were present in $100 \%$ of sampled ciliate-injected fish. They were abundant and in most cases appeared to be clearly viable. From Day 7 onward, the number of ciliateinjected fish in which scuticociliates were not found increased progressively. Ciliates were not found in the coelomic fluid of any of the ciliate-injected turbot sampled on Days 14 and 20 PI.

The presence of scuticociliates in blood smears was only observed from Day 5 up to Day 10 PI (Table 1) and no obvious pattern could be inferred. Results of PCV measurements are presented in Table 2. The data showed a high dispersion that did not allow further statistical analysis. Scuticociliates were not detected in any of the skin scrapings studied.

\section{Histopathology}

\section{Sequence of dissemination of ciliates in tissues}

Scuticociliates were first noticed in histological samples of Day 2 PI. They were observed at low densities in parietal and visceral serosae and between the acini

Table 1. Scophthalmus maximus. Ciliate presence in tissues of sampled turbot (positive/examined [mean ciliate density in positive cases are graded as levels 1 to 3, indicated in parentheses]). Level $1=$ ciliate density presence of at least one ciliate, with up to $2 \%$ of surface examined occupied by ciliates; Level 2 = mild to moderate presence of ciliates, i.e. from 2 to $10 \%$ of surface examined occupied by ciliates; and Level $3=$ high ciliate densities, i.e. $>10 \%$ of the surface examined occupied by ciliates

\begin{tabular}{|c|c|c|c|c|c|c|c|c|c|c|c|c|}
\hline $\begin{array}{l}\text { Day } \\
\text { PI }\end{array}$ & $\begin{array}{l}\text { Coelomic } \\
\text { fluid }\end{array}$ & Pancreas & Serosae & $\begin{array}{l}\text { Digestive } \\
\text { tract }\end{array}$ & Liver & Kidney & $\begin{array}{l}\text { Abdominal } \\
\text { wall }\end{array}$ & Blood & Heart & Spleen & Gills & $\begin{array}{l}\text { Neuro- } \\
\text { cranium }\end{array}$ \\
\hline 1 & $3 / 4(1)$ & $0 / 4$ & $0 / 4$ & $0 / 4$ & $0 / 4$ & $0 / 4$ & $0 / 4$ & $0 / 4$ & $0 / 3$ & $0 / 4$ & $0 / 4$ & $0 / 4$ \\
\hline 2 & $1 / 4(2)$ & $2 / 4(1)$ & $2 / 4(1)$ & $0 / 4$ & $0 / 4$ & $0 / 4$ & $1 / 2(1)$ & $0 / 4$ & $0 / 3$ & $0 / 3$ & $0 / 4$ & $0 / 4$ \\
\hline 3 & $2 / 4(2)$ & $0 / 4$ & $0 / 4$ & $0 / 4$ & $1 / 4(1)$ & $1 / 4(1)$ & $1 / 4(1)$ & $0 / 4$ & $0 / 4$ & $0 / 4$ & $0 / 4$ & $1 / 4(1)$ \\
\hline 4 & $2 / 4(3)$ & $1 / 4(1)$ & $1 / 4(1)$ & $0 / 4$ & $1 / 4(1)$ & $1 / 4$ (1) & $1 / 4(1)$ & $0 / 4$ & $1 / 4(1)$ & $0 / 4$ & $0 / 4$ & $1 / 4(1)$ \\
\hline 5 & $4 / 4(3)$ & $2 / 3(1)$ & $3 / 4$ (3) & $2 / 4(1)$ & $3 / 4(1)$ & $3 / 4$ (1) & $2 / 4(2)$ & $3 / 4(1)$ & $1 / 4(1)$ & $0 / 3$ & $1 / 4(1)$ & $1 / 4(1)$ \\
\hline 6 & $4 / 4(3)$ & $3 / 4(2)$ & $3 / 4(2)$ & $3 / 4(1)$ & $4 / 4(1)$ & 2/3 (1) & $4 / 4(1)$ & $1 / 4(3)$ & $3 / 4$ (1) & $0 / 4$ & $1 / 4(1)$ & $1 / 4(1)$ \\
\hline 7 & $3 / 4(3)$ & $3 / 4(3)$ & $3 / 4(2)$ & $3 / 4(2)$ & $3 / 4(2)$ & $3 / 4$ (1) & $4 / 4(2)$ & $3 / 4(1)$ & $2 / 3(1)$ & 2/4 (1) & $2 / 4(2)$ & $2 / 2(1)$ \\
\hline 8 & $3 / 4(3)$ & $3 / 4(3)$ & $3 / 4(1)$ & $3 / 4(3)$ & $3 / 4(2)$ & $3 / 4$ (1) & $3 / 4(2)$ & $3 / 4(2)$ & $3 / 4$ (1) & 1/4 (1) & $3 / 4$ (1) & - \\
\hline 10 & $2 / 4(3)$ & $1 / 4(3)$ & $2 / 4(1)$ & $2 / 4(2)$ & $2 / 4(2)$ & 2/3 (1) & $4 / 4(1)$ & $2 / 4(1)$ & $2 / 3(1)$ & 1/4 (1) & $2 / 4$ (1) & - \\
\hline 12 & $1 / 4(1)$ & $0 / 4$ & $0 / 4$ & $0 / 4$ & $0 / 4$ & $0 / 4$ & $1 / 4(1)$ & $0 / 4$ & $0 / 4$ & $0 / 4$ & $0 / 4$ & - \\
\hline 14 & $0 / 1$ & $0 / 1$ & $0 / 1$ & $0 / 1$ & $0 / 1$ & $0 / 1$ & $0 / 1$ & $0 / 1$ & $0 / 1$ & $0 / 1$ & $0 / 1$ & - \\
\hline 20 & $0 / 5$ & $0 / 5$ & $0 / 5$ & $0 / 5$ & $0 / 5$ & $0 / 5$ & $0 / 5$ & $0 / 5$ & $0 / 5$ & $0 / 5$ & $0 / 5$ & - \\
\hline
\end{tabular}


Table 2. Scophthalmus maximus. Plasma corpuscular volumes (PCVs) measured in biased sampled fish; results that are clearly inconsistent are indicated in bold text and were not used to calculate mean PCV values

\begin{tabular}{|c|c|c|c|c|c|c|c|c|c|c|c|c|c|}
\hline Day PI & 0 & 1 & 2 & 3 & 4 & 5 & 6 & 7 & 8 & 10 & 12 & 14 & 20 \\
\hline & 37 & - & 31 & 58 & 32 & 36 & 51 & 20 & 27 & 23 & 25 & \multirow[t]{4}{*}{37} & 29 \\
\hline & 24 & - & 36 & 38 & 36 & 34 & 90 & 23 & 22 & 31 & 26 & & 29 \\
\hline & 60 & - & 38 & 65 & 41 & 25 & 74 & 30 & 25 & 20 & 30 & & 36 \\
\hline & & - & 35 & 46 & 37 & 27 & 41 & 24 & 29 & 31 & 33 & & $\begin{array}{l}41 \\
44\end{array}$ \\
\hline Mean & & & 35 & & 36.5 & 30.5 & & 24.3 & 25.8 & 26.3 & 28.5 & & 35.8 \\
\hline
\end{tabular}

of exocrine pancreatic cells. On Days 3 and 4 PI the number of fish showing histological evidence of infection and ciliate densities within the affected areas remained unchanged. However, there was an increase in the range of affected tissues; scuticociliates were first found in liver, kidney and heart cavities, although the presence was occasional and at very low densities. From Days 5 and 6 PI onward ciliate presence became more evident, both in terms of ciliate density and tissues colonized. Occasional presence of ciliates within the parenchyma of other organs was also noticed. The entire digestive tract and abdominal wall were affected. Moreover, the ciliates were observed in gills of 2 fish, although at very low densities. On Days 7 and 8 PI scuticociliate abundance in tissues reached its peak. Pancreas and serosae contained the highest densities, but the number of observed scuticociliates also increased moderately in the liver parenchyma, abdominal wall, digestive tract, heart and gills. Kidneys maintained low ciliate numbers. Ciliates were abundant in the perisplenic tissue, which had remained mostly unaffected on previous days. Only in very few cases were ciliates noticed in the splenic parenchyma, and at very low densities. Presence of ciliates in the heart was erratic. On Day 10 PI only $50 \%$ of turbot examined showed clear evidence of infection. In positive cases ciliate distribution was similar to that observed from samples taken on Days 7 and 8 PI. On Day 12 PI ciliates were seldom noticed, as they were only present in moderate numbers in the abdominal wall of one fish and in the coelomic fluid of another. Ciliates could not be found either in fish sampled on Day 14 PI or in the 5 fish sacrificed on Day 20 PI. More detailed information is provided in Table 1.

\section{Ciliate morphology}

Ciliates showed a teardrop shaped morphology with food vacuoles frequently containing different debris including, in some cases, partially degenerated erythrocytes. Ciliate division stages were also observed.
Ciliate distribution, lesions and immunological response

Pancreas. Both positive samples and high ciliate densities were common in pancreatic tissue, as it was in the case of digestive tract and serosae. A generally intense multifocal distribution of scuticociliates was observed and the organisms were usually present within the connective tissue. The inflammatory response was especially intense and evident even before ciliates were noticed, and was still persistent at the end of the experiment. The response consisted mainly of a granulocyte infiltration and presence of macrophages aggregates (Fig. 2) containing unstained amorphous cellular debris. A certain degree of fibrosis was also found, especially in samples from the final days.

Serosae. Scuticociliates tended to be attached to the serosa or located just between the epithelium and the underlining tissues. However, not all serosae were affected equally. In some organs, such as the pancreas and digestive tract, serosae were rapidly and

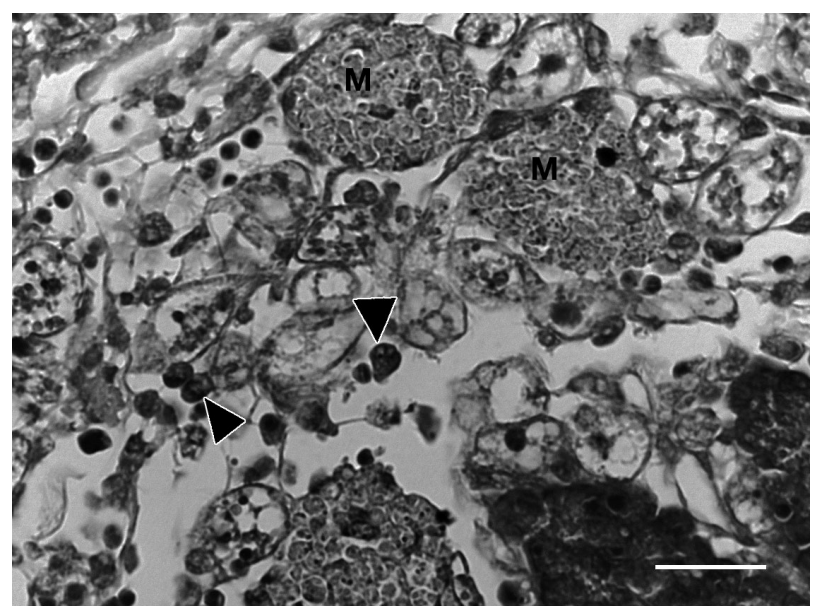

Fig. 2. Scophthalmus maximus. Ciliate invasion and inflammatory response in the pancreas. A massive presence of ciliates and a significant inflammatory reaction, consisting of aggregates of macrophages (M) and an infiltration with small and intensively basophilic leukocytes (arrowheads), have almost obscured the parenchyma. Scale bar $=20 \mu \mathrm{m}$ 
intensively colonized, while in others, such as liver, abdominal wall, kidney or spleen, ciliates were seldom found. Local reaction was variable; in some locations regardless of the organ, an acute inflammatory response consisting mainly of groups of macrophages was observed, while in others no evidence of inflammation was noticed despite the abundance of scuticociliates present.

Digestive tract. The distribution of ciliates among the different layers of digestive tract tissue was not uniform. When the densities observed were low, the scuticociliates were usually detected only under the serosae and adjacent underlying layers. The submucosal and subserosal layers were the most affected, having the highest ciliate densities, followed by serosae and finally the muscle layers, which were the least frequently and severely affected (Figs. 3 \& 4). No ciliates were found within the intestinal epithelia, although in the most severe cases the basal lamina was affected and haemorrhagic areas were also identified. Mucosal detachment was occasionally observed. As a rule, the inflammatory response was directly related to ciliate density except for the final days PI when, in some cases, the response persisted conspicuously even after the scuticociliates had disappeared. The inflammatory response in the intestine consisted mainly of accumulations of macrophages that could also project from the serosal up to the submucosal layer (Figs. 4 \& 5), and in some cases granulocyte infiltration. Although all layers could be affected, granulocyte infiltration was usually denser at the submucosae level, especially perivascularly

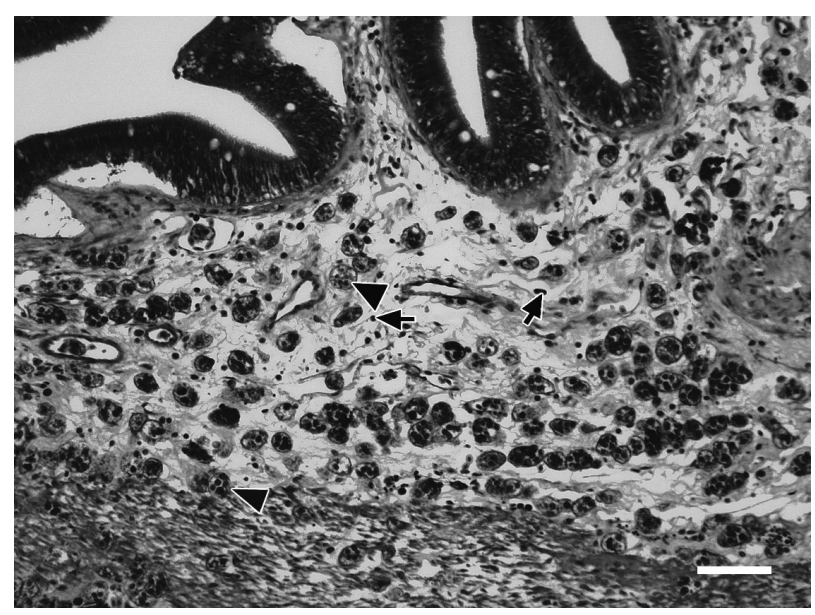

Fig. 3. Scophthalmus maximus. Ciliate invasion of the digestive tract. Ciliates (arrowheads), easily identifiable due to the presence of erythrocytes in food vacuoles, show a denser distribution in submucosa. However, they are also found in the muscle layer. Small and intensively basophilic leukocytes (arrows) are also distinguishable at the submucosa level. Scale bar $=50 \mu \mathrm{m}$

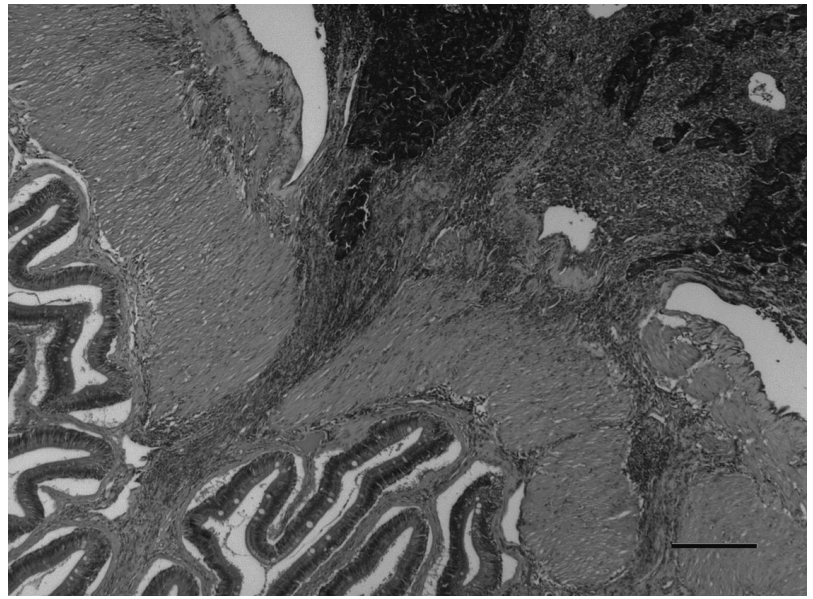

Fig. 4. Scophthalmus maximus. Inflammatory reaction in the digestive tract. A mass of partially degenerated leukocytes and ciliates deepens from serosa and pancreatic tissue up to submucosa. Scale bar $=150 \mu \mathrm{m}$

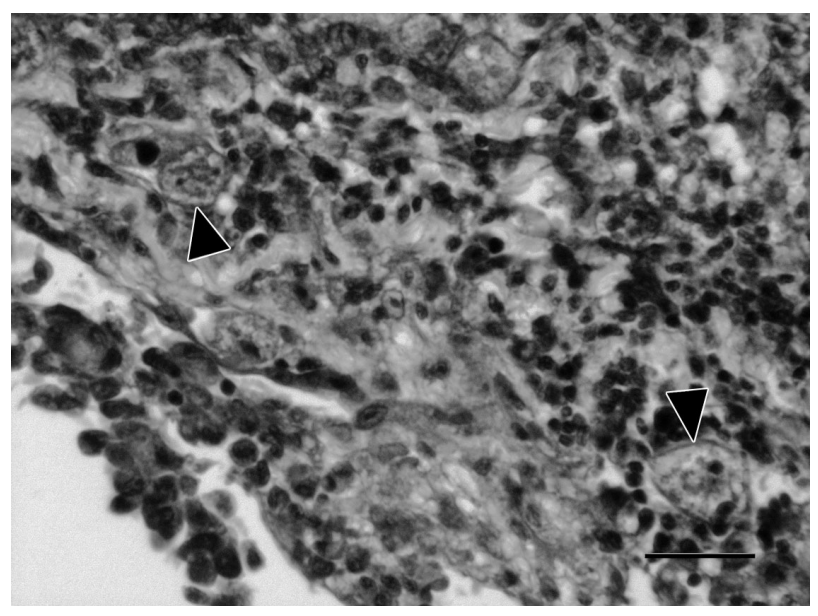

Fig. 5. Scophthalmus maximus. Inflammatory reaction in the digestive tract. Detail of the degenerated mass of inflammatory cells and ciliates (arrowheads) from Fig. 4 at higher magnification. Scale bar $=20 \mu \mathrm{m}$

(Fig. 6). Aggregates of macrophages containing unstained amorphous cellular debris were also found occasionally at the submucosa, especially just under the basal lamina of mucosal folds.

Abdominal wall. Presence of ciliates with medium to high densities was common at this location in the examined sections. Although no clear pattern of diffusion could be inferred, ciliates tended to concentrate at specific sites. Ciliates were observed beneath serosae (Fig. 7), between the dermis and skeletal muscular layer (Fig. 8), among the collagen fibres of the loose dermis and in the myotomal septa of the skeletal muscular layers (Fig. 8). A mild inflammatory response consisting of a diffuse granulocyte infiltration of vari- 


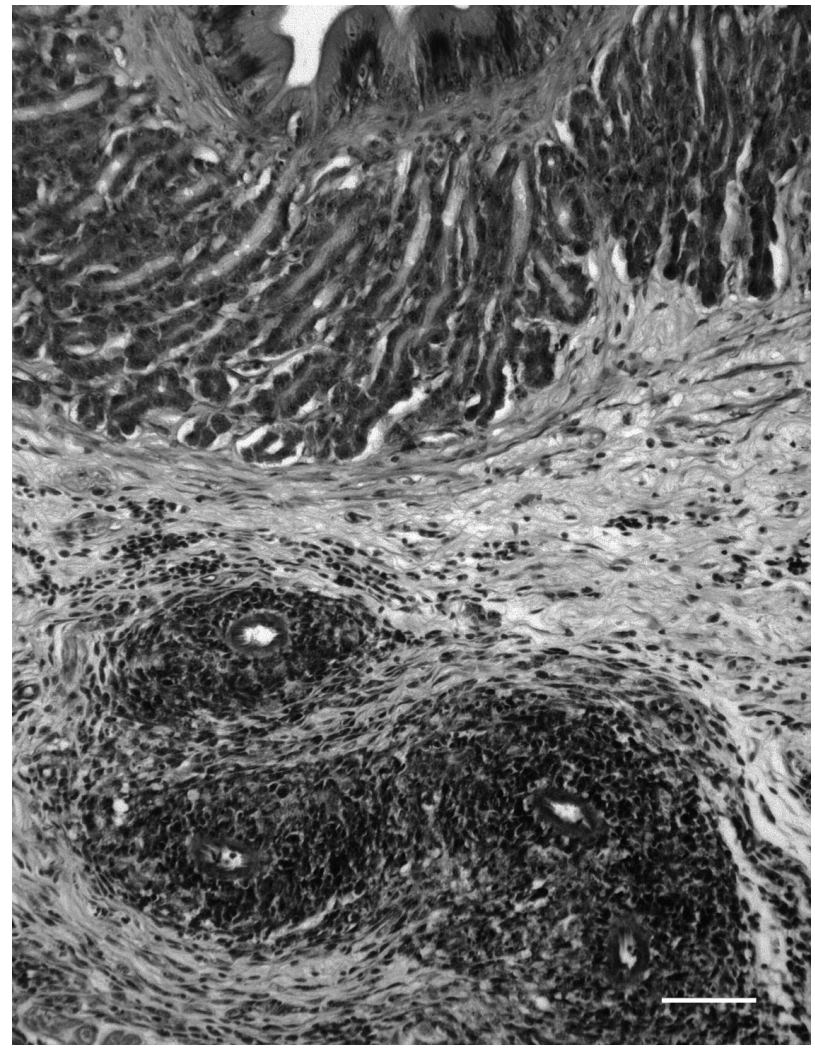

Fig. 6. Scophthalmus maximus. Inflammatory reaction in the stomach. Perivascular infiltration of small and intensively basophilic leukocytes. Scale bar $=50 \mu \mathrm{m}$

able intensity was detected. This response persisted, although it was less intense, in the fish sacrificed on Day 20 PI. In addition, aggregates of macrophages were noticed projecting from the serosae upward to outer layers in some specimens.

Liver. Although positive samples were common, high ciliate densities were seldom found in the liver. The ciliates were usually located beneath serosae and in the connective tissue surrounding bile ducts and vascular vessels (Fig. 9). Only occasionally were they also observed within the parenchyma. The inflammatory response consisted of an occasional, mild granulocyte infiltration and, in some cases, presence of macrophage aggregates accumulating unstained amorphous cellular debris. A clear fibrotic response was noticed in a single fish sacrificed on Day 20 PI.

Kidney. As in the liver, positive kidney samples were common, but the ciliate densities remained markedly low. Haemorrhages were particularly frequent, as was an alteration of the interstitial tissue, which consisted of a diffuse presence of granulocytes in all of the examined parenchyma. This alteration was clearly evident even in cases in which ciliate presence was limited to the serosae level.

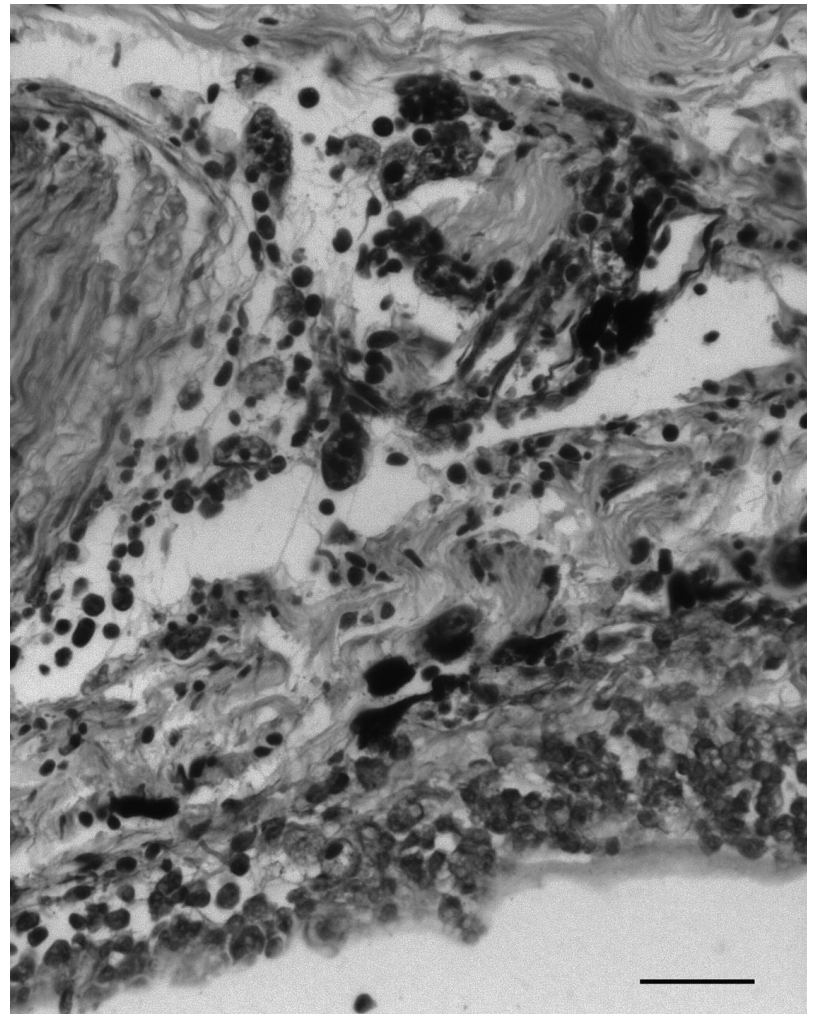

Fig. 7. Scophthalmus maximus. Ciliates located in parietal serosa of the abdominal wall. Note also the leukocyte infiltration and the macrophages attached to the serosa. Scale bar $=30 \mu \mathrm{m}$

Heart. The heart was not affected frequently, nor did it show high ciliate densities. When scuticociliates were found, they were mainly between myocardic trabeculae (Fig. 10), especially in the atrium. In these cases granulocytemia was observed. Surprisingly, presence of ciliates within heart blood cavities did not correspond with blood smear data. Only in very few cases were scuticociliates found within the myocardium, and only in very small numbers. These incidents corresponded with an overall high level of infection. Ciliates were also found under serosae and endothelia (Fig. 10).

Gills. Ciliate presence was rare in gill tissue. When found, their incidence was related to a high presence of scuticociliates in the other fish tissues. Ciliates were only seen intravascularly (Fig. 11). A diffuse granulocyte infiltration and an accumulation of macrophage aggregates in the terminal end of secondary lamellae were noticed (Fig. 12). Neither of these 2 responses was consistent with ciliate presence in the organ.

Neurocranium. Unfortunately almost half of the samples of neurocranium tissue corresponding to Days 7 (2 samples), 8, 10, 12, 14 and 20 PI were lost during the processing. In the remaining samples ciliates were 
found in 6 fish (corresponding to overall high ciliate densities in the other tissues), but they were always scarce. The inflammatory response was unappreciable at this location.

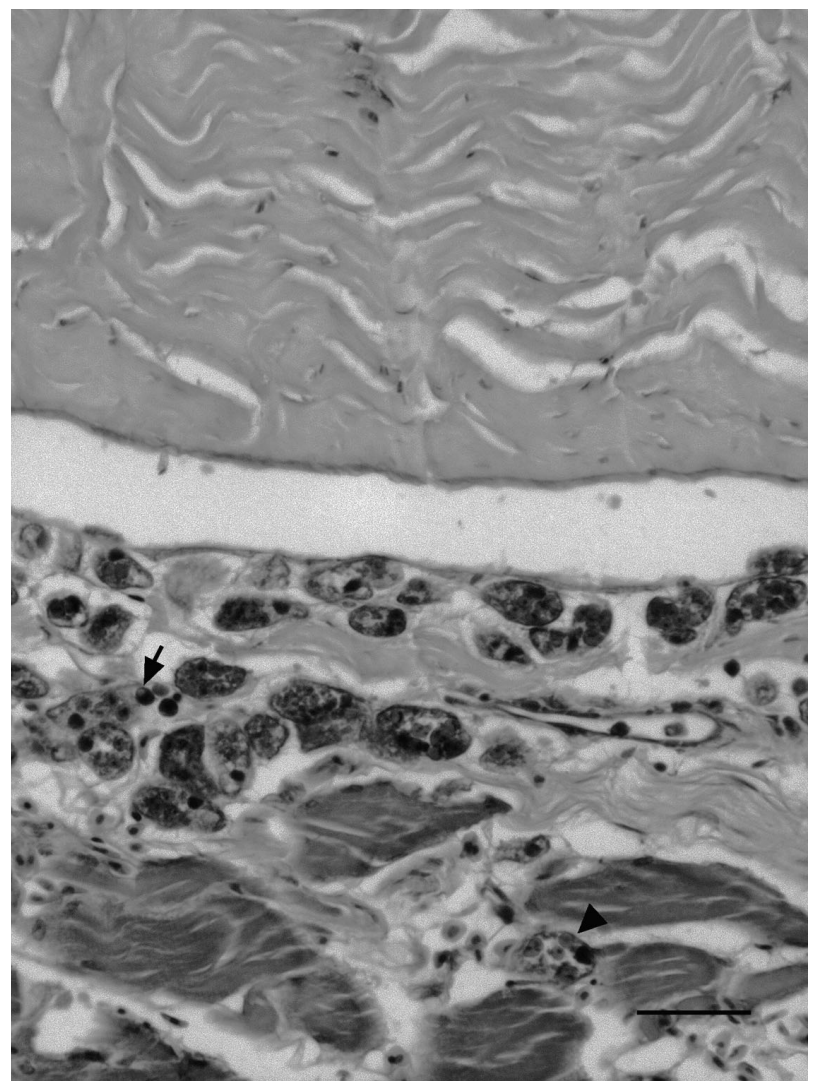

Fig. 8. Scophthalmus maximus. Ciliates located between dermis and skeletal muscular layer and in the myotomal septa of the muscular layer (arrowhead) of the abdominal wall. Note also the mild leukocyte infiltration (arrow). Scale bar $=30 \mu \mathrm{m}$

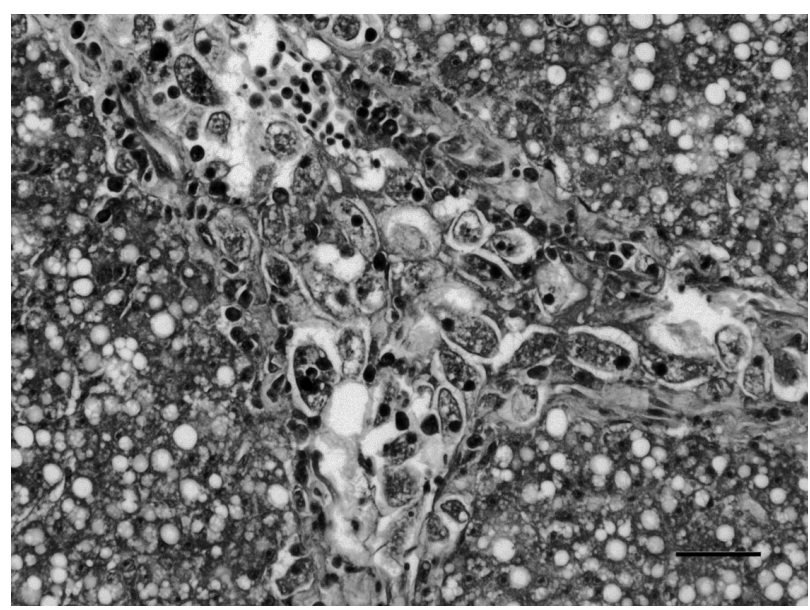

Fig. 9. Scophthalmus maximus. Ciliates in the liver stroma. Note also the infiltration with leukocytes. Scale bar $=30 \mu \mathrm{m}$

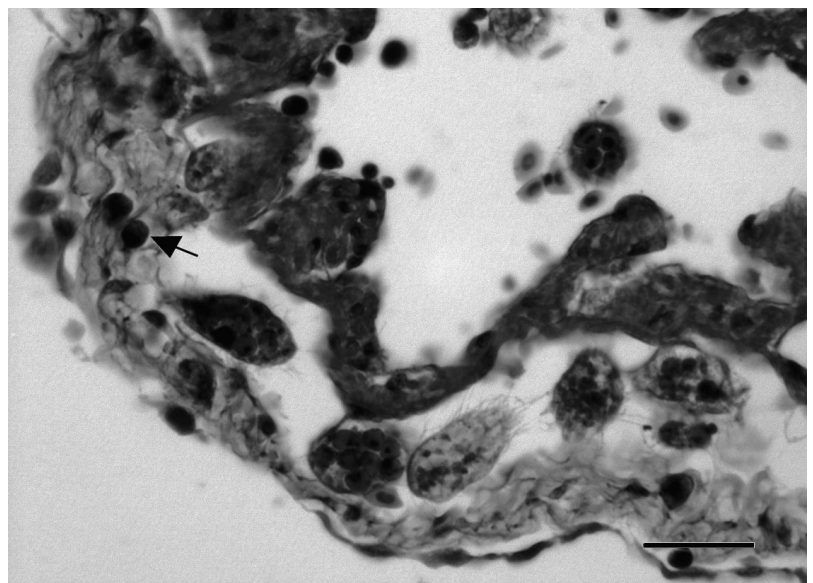

Fig. 10. Scophthalmus maximus. Ciliates in the vascular spaces of the atrium in the heart and between pericardium and myocardium. Note also the increased presence of leukocytes (arrow). Scale bar $=20 \mu \mathrm{m}$

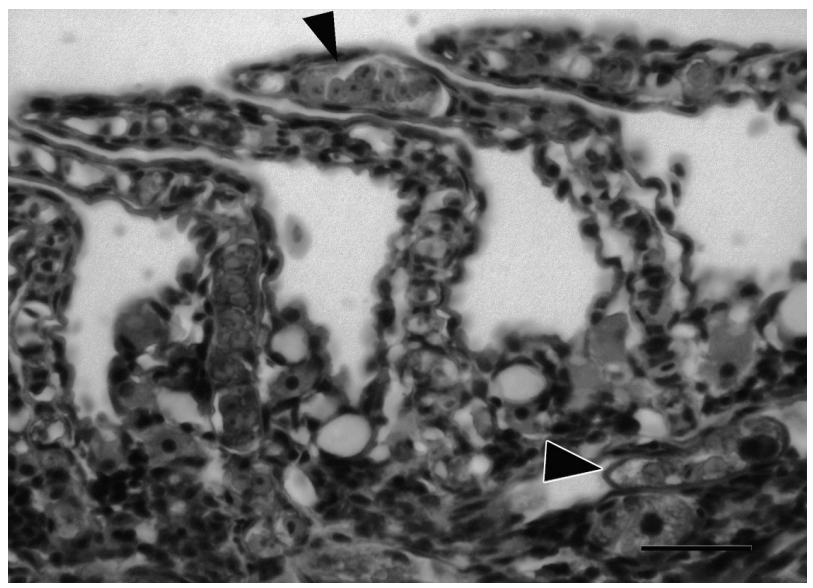

Fig. 11. Scophthalmus maximus. Ciliates (arrowheads) in the vascular spaces of the gills. Scale bar $=20 \mu \mathrm{m}$

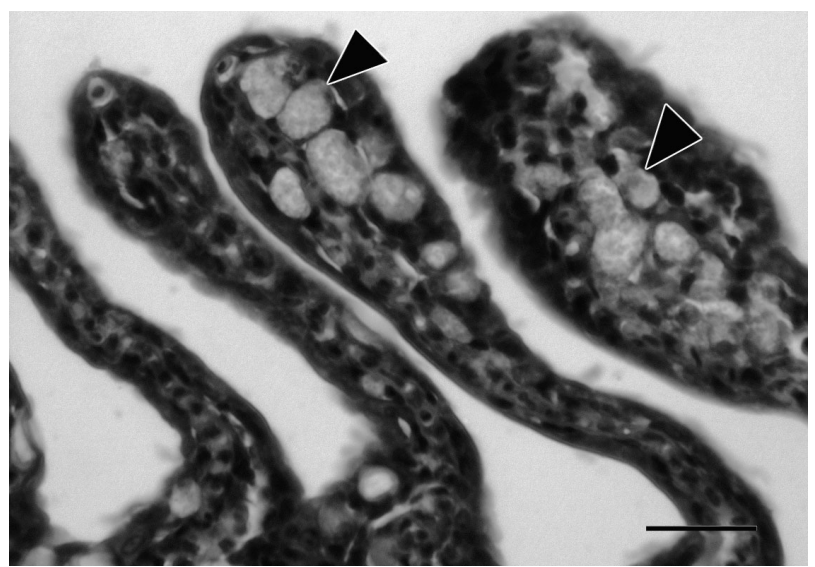

Fig. 12. Scophthalmus maximus. Aggregates of macrophages (arrowheads) in the vascular spaces of the gills. Scale bar = $20 \mu \mathrm{m}$ 
Spleen. In the perisplenic tissue (consisting of serosa folds and pancreatic tissue) ciliate densities were as high as those observed for pancreas and serosae, although they appeared later after treatment. The inflammatory reaction was also equivalent to that described for pancreas and serosae. Within the splenic parenchyma, ciliates were only found in 4 cases out of 47, and in extremely low numbers. Variable spleen reaction was observed in some cases, and did not always correspond with ciliate densities. The response consisted of an increase in size of the ellipsoids, congestion and an increase of leukocyte aggregates.

\section{DISCUSSION}

The intracoelomic inoculation method and the sampling frequency were selected according to Paramá et al. (2003) and our own previous experiments (ÁlvarezPellitero et al. 2004, and data not shown). Although artificial, this route facilitates fixing precisely the number of viable ciliates that will reach the internal medium. This approach also is easy and rapid to perform and, therefore, less traumatic for the fish.

The results of this research indicate that ciliate infection followed a progressive pattern in almost every aspect examined. As the infection developed the scuticociliates increased in number, affecting a wider diversity of organs and tissues and provoking more severe lesions and inflammatory reactions. The infection increased from Day 1 up to Day 8 PI, after which a progressive regression of the infection was observed. Ciliates dividing by binary fission were commonly found in ciliate injected fish. Fish mortality was concentrated between Days 7 and 11 PI. From these results it seems clear that ciliates feed on and multiply inside the fish up to the host's death or up to their elimination by the host's immune system. It is also apparent that viable scuticociliates do not survive for long after the fish die. This finding contradicts Iglesias et al.'s (2004) view that cadavers act as a food source for ciliates in the water and as a source of infection for other fish. The course of infection was particularly rapid in this experiment, which contrasts with the extremely slow progression observed in American lobster Homarus americanus (Athanassopoulou et al. 2004), probably because the rearing temperatures of $H$. americanus were rather lower. The infection in turbot became systemic on Day 5 PI and from Day 12 onward there was already evidence of regression. Moreover, the total absence of ciliates in samples collected on Day 20 PI suggests that the infection does not become chronic. These observations suggest the lack of a well-balanced host-parasite relationship. Therefore, scuticociliatosis in turbot occurs apparently as an accidental parasitosis with attributes of an emerging disease including (1) recent and frequent description of outbreaks (Dyková \& Figueras 1994, Sterud et al. 2000, Iglesias et al. 2001), (2) high mortalities such as those recorded in these outbreaks, (3) the rapid course of the disease and (4) the inexistence of an equilibrium in the host-parasite relationship. We observed all of these features in our experiment.

Ciliate distribution in the host tissues was similar to that reported in natural infections in flatfishes (Dyková \& Figueras 1994, Sterud et al. 2000, Iglesias et al. 2001, Jee et al. 2001). However, the presence of similar protozoans in brain and gills and the description of macroscopic ulcers frequently reported during natural outbreaks in flatfishes and other fish species (Munday et al. 1997, Sterud et al. 2000, Iglesias et al. 2001, Jee et al. 2001, Kim et al. 2004) were not observed in our experiment. This pattern possibly relates to the route of experimental infection we used being different to the natural one.

Iglesias et al. (2001) proposed blood as one possible dissemination route within fish tissues and Paramá et al. (2004b) demonstrated its chemoattractant properties for scuticociliates. In this experiment parasitaemia showed low and erratic values although ciliates were frequently observed intravascularly and perivascularly, and well-vascularized organs distant from the inoculation point (such as brain and gills) were affected rarely and late in the infection's progress. If the bloodstream were a major dissemination route higher ciliate numbers in peripheral blood and in organs with porta vascular systems or filtration functions, such as liver, kidney, gills and spleen, would be expected. In the latter scuticociliates were only observed in 4 samples out of all 47 ciliate-injected fishes. At least an early colonization of these organs should have been observed. It is common understanding that ciliates use the bloodstream to invade other organs, but our results point to different and possibly more significant ways of diffusion into the tissues. In our work ciliates were observed mainly between loose connective tissue structures during the entire course of the infection. Considering this specific tropism and the fact that in most organs stromal connective tissue is very abundant, the infection can also progress and extend to adjacent organs through the connective tissues. Proteases, including cathepsine B and metalloproteases, have been demonstrated in parasitic scuticociliates and their importance during ciliate invasion and pathogenesis has been suggested (McKerrow 1989, Lee et al. 2003, Small et al. 2005). This fact coupled with observations by others of high numbers of scuticociliates present on gill and brain in spontaneous infections points to a natural percutaneous-pernasalperorbital route of infection, which was suggested by Sterud et al. (2000) and also by Munday et al. 
(1997) in southern bluefin tuna Thunnus maccoyii infected with Uronema nigricans.

Despite the high dispersion of PCV measures, a certain decrease during the course of the infection was observed. This tendency to anaemia is consistent with the haematophagous activity of scuticociliates (Purdom \& Howard 1971, Cheung et al. 1980, Dyková \& Figueras 1994, Iglesias et al. 2001, Jee et al. 2001). However, food vacuoles did not always contain erythrocytes, as observed by Dragesco et al. (1995). This implies a more generic histophagous activity rather than an exclusively haematophagous one.

Patterns of inflammation varied depending on the organ. Given the characteristics of turbot peripheral leukocytes (Burrows et al. 2001) lymphocytes can be easily confused with thrombocytes. In addition, cytoplasm of round granulocytes was dark in colour in our H\&E stains. Only 3 patterns of inflammatory response could be easily recognized: (1) macrophage infiltration; (2) aggregates of macrophages with accumulations of unstained amorphous cellular debris; and (3) infiltrations with strongly basophilic small cells. Very few of the latter could be easily classified as granulocytes or lymphocytes, even when examined at high magnification. Iglesias et al. (2003) gave in vivo evidence of the existence of turbot adaptive immunity to scuticociliates, opening the way to the development of vaccines. Leiro et al. (2004b) and Kwon et al. (2002) studied some ex vivo interactions between scuticociliates and flatfish phagocyte responses. Bearing in mind the fish used in our experiment were naïve and differences existed between controls and ciliate injected fish in terms of mortality and lesions, our data provide 2 in vivo clues that point to a probable partial effectiveness of turbot innate immunity against scuticociliates: (1) A significant number of ciliate-injected fish (16 out of 47) showed an inflammatory reaction in different tissues despite ciliate absence; (2) High ciliate numbers in the coelomic fluid were only observed from Day 4 PI onward. A comparative study of the in vivo effectiveness of humoral and cellular immunities would help define more precisely which prophylaxis strategies should be developed. The saprophytic ciliates have been generally considered as opportunists (Álvarez-Pellitero et al. 2004). However, the mechanisms leading to pathogenic activation of the ciliates and how they persist in the ecosystem have yet to be determined.

Acknowledgements. L.P. receives economic support from the Departament d'Universitats, Recerca i Societat de la Informació of the Generalitat de Catalunya and the European Social Fund. The authors thank Stolt Sea Farm and L. Tort for making the experiment feasible, as well as E. Bautista for her support. This work was funded by the Spanish Government (PTR1995-0604-OP-02).

\section{LITERATURE CITED}

Álvarez-Pellitero P, Palenzuela O, Padrós F, Sitjà-Bobadilla A, Riaza A, Silva R, Arán J (2004) Histophagous scuticociliatids (Ciliophora) parasitizing turbot Scophthalmus maximus: morphology, in vitro culture and virulence. Folia Parasitol 51:177-187

Armstrong DA, Burreson EM, Sparks AK (1981) A ciliate infection (Paranophrys sp.) in laboratory-held Dungeness crabs, Cancer magister. J Invertebr Pathol 37:201-209

Athanassopoulou F, Speare D, Cawthorn RJ, MacMillan R, Despres B (2004) Pathology of Anophryoides haemophila (Scuticociliatida: Orchitophryidae), parasite of American lobster Homarus americanus kept under experimental conditions. Aquaculture 236:103-117

Burrows AS, Fletcher TC, Manning MJ (2001) Haematology of the turbot, Psetta maxima (L.): ultrastructural, cytochemical and morphological properties of peripheral blood leucocytes. J Appl Ichthyol 17:77-84

Cheung PJ, Nigrelli RF, Ruggieri GD (1980) Studies on the morphology of Uronema marinum Dujardin (Ciliatea: Uronematidae) with a description of the histopathology of the infection in marine fishes. J Fish Dis 3:295-303

Dragesco A, Dragesco J, Coste F, Gasc C, Romestand B, Raymond JC, Bouix G (1995) Philasterides dicentrarchi, n. sp., (Ciliophora, Scuticociliatida), a histophagous opportunistic parasite of Dicentrarchus labrax (Linnaeus, 1758), a reared marine fish. Eur J Protistol 31:327-340

Dyková I, Figueras A (1994) Histopathological changes in turbot Scophthalmus maximus due to histophagous ciliate. Dis Aquat Org 18:5-9

Iglesias R, Paramá A, Álvarez MF, Leiro J, Fernández J, Sanmartín ML (2001) Philasterides dicentrarchi (Ciliophora, Scuticociliatida) as the causative agent of scuticociliatosis in farmed turbot Scophthalmus maximus in Galicia (NW Spain). Dis Aquat Org 46:47-55

Iglesias R, Paramá A, Âlvarez MF, Leiro J, Sanmartín ML (2002) Antiprotozoals effective in vitro against the scuticociliate pathogen Philasterides dicentrarchi. Dis Aquat Org 49:191-197

Iglesias R, Paramá A, Álvarez MF, Leiro J, Ubeira FM, Sanmartín ML (2003) Philasterides dicentrarchi (Ciliophora: Scuticociliatida) expresses surface immobilization antigens that probably induce protective immune responses in turbot. Parasitology 126:125-134

Jee BY, Kim YC, Park MS (2001) Morphology and biology of parasite responsible for scuticociliatosis of cultured olive flounder Paralichthys olivaceus. Dis Aquat Org 47:49-55

Kim SM, Cho JB, Kim SK, Nam YK, Kim KH (2004) Occurrence of scuticociliatosis in olive flounder Paralichthys olivaceus by Phiasterides dicentrarchi (Ciliophora: Scuticociliatida). Dis Aquat Org 62:233-238

Kwon SR, Kim CS, Chung JK, Lee HH, Kim KH (2002) Inhibition of chemiluminescent response of olive flounder Paralichthys olivaceus phagocytes by the scuticociliate parasite Uronema marinum. Dis Aquat Org 52:119-122

Lee EH, Kim CS, Cho JB, Ahn KJ, Kim KH (2003) Measurement of protease activity of live Uronema marinum (Ciliata: Scuticociliatida) by fluorescence polarization. Dis Aquat Org 54: 85-88

Lee EH, Kim SM, Kwon SR, Kim SK, Nam YK, Kim KH (2004) Comparison of toxic effects of nitric oxide and peroxynitrite on Uronema marinum (Ciliata: Scuticociliatida). Dis Aquat Org 58:255-260

Leiro J, Arranz JA, Paramá A, Álvarez MF, Sanmartín ML (2004a) In vitro effects of the polyphenols resveratrol, mangiferin and (-)-epigallocatechin-3-gallate on the scu- 
ticociliate fish pathogen Philasterides dicentrarchi. Dis Aquat Org 59:171-174

Leiro J, Arranz JA, Iglesias R, Ubeira FM, Sanmartín ML (2004b) Effects of the histiophagous ciliate Philasterides dicentrarchi on turbot phagocyte responses. Fish Shellfish Immunol 17:27-39

Lynn DH, Small EB (2000) Phylum Ciliophora. In: Lee JL, Leedale GF, Bradbury P (eds) An illustrated guide to the Protozoa, 2nd edn. Society of Protozoologists, Allen Press, Lawrence, KS, p 371-656

McKerrow JH (1989) Parasite proteases. Exp Parasitol 68: 111-115

Munday BL, O'Donoghue PJ, Watts M, Rough K, Hawkesford $T$ (1997) Fatal encephalitis due to the scuticociliate Uronema nigricans in sea-caged, southern bluefin tuna Thunnus maccoyii. Dis Aquat Org 30:17-25

Paramá A, Iglesias R, Álvarez MF, Leiro J, Aja C, Sanmartín ML (2003) Philasterides dicentrarchi (Ciliophora, Scuticociliatida): experimental infection and possible routes of entry in farmed turbot (Scophthalmus maximus). Aquaculture 217: 73-80

Paramá A, Iglesias R, Álvarez F, Leiro JM and 5 others (2004a) In vitro efficacy of new antiprotozoals against Philas-

Editorial responsibility: Dieter Steinhagen,

Hannover, Germany terides dicentrarchi (Ciliophora, Scuticociliatida). Dis Aquat Org 62:97-102

Paramá A, Iglesias R, Álvarez MF, Sanmartín ML, Leiro J (2004b) Chemotactic responses of the fish-parasitic scuticociliate Philasterides dicentrarchi to blood and blood components of the turbot Scophthalmus maximus, evaluated using a new microplate multiassay. J Microbiol Methods $58: 361-366$

Purdom CE, Howard AE (1971) Ciliate infestations: a problem in marine fish farming. J Cons Int Explor Mer 33: 511-514

Small HJ, Neil DM, Taylor AC, Coombs CH (2005) Identification and partial characterization of metalloproteases secreted by a Mesanophrys-like ciliate parasite of the Norway lobster Nephrops norvegicus. Dis Aquat Org 67: $225-231$

Sterud E, Hansen MK, Mo TA (2000) Systemic infection with Uronema-like ciliates in farmed turbot, Scophthalmus maximus (L.). J Fish Dis 23:33-37

Yoshinaga T, Nakazoe J (1993) Isolation and in vitro cultivation of an unidentified ciliate causing scuticociliatosis in Japanese flounder (Paralichthys olivaceus). Fish Pathol 28:131-134

Submitted: April 6, 2006; Accepted: October 6, 2006 Proofs received from author(s): June 19, 2007 